\title{
Students' Motivations and Course Completion in MOOCs
}

\author{
Jieyan Xiao ${ }^{1}$ and Wen Dong ${ }^{1}$ \\ ${ }^{1}$ Hang Zhou Normal University, China
}

Keywords: MOOC; Motivations; Higher education; Course completion

\begin{abstract}
Massive open online courses (MOOCs) has been sweeping the world's higher education in recent years for the teaching and learning of different subjects. However, MOOCs typically have low completion rates, at least when compared with traditional courses. Students motives for gaining skills, ideas and inspirations, and develops their professional abilities. This paper will analyze the relationship between students' motivations and course completion in MOOCs, especially focusing on how learners' motivations for taking a MOOC influence their course completion. By reviewing quite a lot of literatures and taking the contrast experiments, we will discuss our work to study the motivational differences between students who complete the course and those who do not. We find that various students' motivations are affecting their course completion in a MOOC. It will supply with some supporting evidence for course instructors who can make adjustments to a MOOC course according to students' motivations.
\end{abstract}

\section{Introduction}

MOOC came to prominence in 2012 and have been successful in attracting tens of thousands of students [1].Massive Open Online Courses(MOOCs) are providing students from all over the world the learning resources and opportunities. It pays attention to the integration of excellent teaching resources and sets the revolutionary educational model for educators in such digital information age. Higher educators are using the high-quality teaching resources to promote information exchanging and sharing. However, the concern is growing that MOOCs have not had as immediate or as profound an impact on education as initially anticipated [2].This paper investigates some kinds of possible motivations for students' engagement in a MOOC. The following literature review addresses the topic of motivations to learn in online learning environment and the influence on the course completion.

\section{Background}

Siemens [3] and Downes [4], the first developers of the original MOOC concept, proposed a theory of connectivism by a technological and social network of multiple connections and experiences. MOOCs have been developed independently by university-based academics among higher educational institutions and have succeeded in attracting tens of thousands of students [5]. With no formal requirements for entry, MOOCs aims to complement the traditional university education rather than replace it. However, someone who against MOOCs has expressed concern that the massive number of enrolled students will make it difficult for higher educators to teach effectively. So some universities that offered MOOCs now have returned to smaller online courses with a closed application process [6].

Question have been put forward about MOOCs including free registration, open access to learning and a large number of students who not only have different levels but also wide ranging motivations for taking a course. Many researches on learning motivations have payed attention to understanding the low completion rates [7]. The course completion rates have been regarded as the percentage of students who received a certificate for the course. Despite of university experience or course content, the course completion rate has been low, frequently between 5 to $10 \%$ [8]. Many people hold the opinion that low completion rates are related to course length and students' motivations. Through many conducted experiments, non- completers invest less time in the early time of the course and spend less time on assessment than completers. 


\section{The Relationship between Students' Motivations and Course Completion in MOOCs}

Given that MOOCs are becoming more and more popular worldwide, students' motivations should be further studied from many aspects. Motivation refers to a reason or a goal a person has for behaving in a given manner in a given situation. Motivation is conceptualized as an internal source which enhances, maintains, or mediates cognitive development [9]. It is part of a person's objectives and beliefs about what is important or not [10]. It determines whether a person will have a certain interest or be engaged in a certain activity or not.

Glynn and friends indicated that there are several motivations that influence learning such as intrinsic and extrinsic motivation, self-efficacy, and self-determination and so on. Intrinsic motivation refers to an inherent gratification promoted by the feeling that learning is interesting and enjoyable. Extrinsic motivation refers to some external incentives for learning such as much stress or a reward. Self-efficacy refers to students' confidence that they can finish on their own. And self-determination refers to the control students' believe they have over their learning process.

In the context of MOOCs, students tend to choose course content following their goals and interests. For examples, someone found that non-completers tend to be more interested in MOOCs as a type of learning experience, while completers are more interested in the course content. In addition, people also find that students who enrolled with friends are more likely to be engaged than their counterparts. Besides these results, we find some relationships between the students' motivations and course completion with the potential to inform future intervention for both students and instructors:

1. Mastery-oriented motivations and academic self-efficacy were not useful to predict whether a student will complete the course successfully or not. Students are more willing to choose to take a MOOC for no formal credit.

2. Students who are more interested in the MOOC learning environment as a new learning platform than course content will less likely to complete the MOOC course. Generally speaking, their motivations to enroll the courses are something like "Course is offered by a prestigious university" or "Geographically isolated from educational institutions"[11].

3. Early self-confidence in completing the course is a successful predictor of whether a student will complete the course or not. We can say that the students with more confidence will be more likely to complete the course.

4. From the beginning of the course, students who are self-identified as non-English native speakers show higher confidence in completing the course than native speakers. However, it does not matter the course completion.

\section{Conclusions}

Given the current "knowledge economy", and the growing importance of lifelong learning, it is necessary to doubt whether we should focus on certificates at all. We should take some measures to move beyond extrinsic motivations and examine the intrinsic motivations. Most students take a MOOC course with the aim to learn something useful rather than complete the course. The students' motivations and course completion suggest that MOOCs can appeal to students from diverse educational backgrounds.

Considering these findings, we can make a conclusion that course completion can be used to study persistent and learning in the context of MOOCs. Furthermore, MOOCs challenge many traditional education modes. In doing so, they question traditional pathways, purposes and outputs in education. Therefore, our research suggests that students' initial motivations can play an important role in whether students persist in and complete a MOOC.

Understanding the relationships between the students' motivations and course completion is important for both students and teachers. Teachers can better understand design the MOOC courses according to students' different motivations, and thus, take effective actions to develop the course completion. 


\section{References}

[1] Pappano L. The year of the MOOC (New York Times, New York 2012).

[2] Gillani N, Eynon R: The Internet and Higher Education, (2014) No.23, p.18-26.

[3] Information on http://www.elearnspace.org.

[4] Downes S. Media, Knowledge and Education - Exploring new Spaces, Relations and Dynamics in Digital Media Ecologies (Innsbruck University Press, Innsbruck2008).

[5] UK Universities. Massive Open Online Courses: Higher Education's Digital Moment? (Universities UK, London2013).

[6] Baggaley J. MOOC Rampant (Distance Education, America 2013).

[7] Jordan K: The International Review of Research in Open and Distributed Learning, Vol. 15 (2014) No.1, p.133-160.

[8] Parkinson D. Implications of a new form of online education. (Nursing Times. UK 2014), p.110.

[9] Brophy J: British Journal of Educational Technology, Vol. 41 (2010) No.6, p.160.

[10] Ames C: Journal of Educational Psychology, Vol. 84 (1992) No.3, p.261-271.

[11] Information onhttp://www.moocworkshop.org. 